\title{
Rhinosinusitis in COPD: symptoms, mucosal changes, nasal lavage cells and eicosanoids
}

This article was published in the following Dove Press journal:

International Journal of COPD

21 April 2010

Number of times this article has been viewed

\author{
Violetta M Piotrowska' \\ Wojciech J Piotrowski ${ }^{2}$ \\ Zofia Kurmanowska ${ }^{2}$ \\ Jerzy Marczak² \\ Paweł Górski \\ Adam Antczak ${ }^{2}$ \\ 'Department of Pediatric \\ Otolaryngology, Medical University \\ of Lodz, Poland; ' 2 Department \\ of Pneumology and Allergy, Medical \\ University of Lodz, Poland
}

Correspondence: Adam Antczak Department of Pneumology and Allergy, Medical University of Łódź, Kopcińskiego 22, 90-153 Łódź, Poland

Fax +48 426782129

Email adam.antczakl@wp.pl
Abstract: The coexistence of upper airways disease with chronic obstructive pulmonary disease (COPD) is not well documented. The aim of this research was to assess sino-nasal inflammation in COPD by various tools, and look for the impact on quality of life, relation to smoking, disease severity and systemic inflammation. Current and ex-smokers with COPD $(n=42)$ and healthy never-smokers $(\mathrm{n}=21)$ were included in this study. COPD severity was assessed by GOLD criteria and BODE index. Markers of systemic inflammation were measured. Nasal symptoms and general quality of life were assessed using the questionnaires; sino-nasal questionnaire (SNAQ-11) and St. George's Respiratory Questionnaire (SGRQ). Nasal endoscopy and saccharine test were performed. Nasal lavages were collected for cytological examination and eicosanoids (cysteinyl leukotrienes, leukotriene B4, 8-isoprostane). Symptoms and endoscopic scores were higher in COPD $(P \leq 0.0001)$. Only SGRQ symptoms subscore correlated with SNAQ-11 $(\mathrm{r}=0.34, P=0.035)$. Mucociliary clearance was impaired only in current smokers $(9.91 \pm 0.49$ versus $13.12 \pm 0.68$ minutes, $P \leq 0.001)$. 8 -isoprostane was higher in COPD smokers compared to the controls $(0.17 \pm 0.04$ versus $0.34 \pm 0.09 \mathrm{pg} / \mathrm{g}$ protein, $P<0.05)$. Endoscopic score and mucociliary of impairment patients who currently smoked cigarettes correlated with concentrations of 8-isoprostane. None of the parameters correlated with disease severity and markers of systemic inflammation. We provide evidence of upper airways disease in COPD, which appears to be related more to patients who currently smoke than to disease severity.

Keywords: chronic obstructive pulmonary disease, eicosanoids, nasal lavage, rhinitis, smoking, upper airways disease

\section{Introduction}

The close relationship between asthma, allergic and nonallergic rhinosinusitis and nasal polyps has been acknowledged for many years. It has been estimated, that approximately $90 \%$ of allergic asthmatics suffer from rhinitis, and around $30 \%$ of rhinitis patients suffer from asthma. ${ }^{1}$ The theory of "united airway" or "common airway disease" has been formulated and described in several review papers and monographs. ${ }^{2-4}$ For many years the problem of upper airways pathology in patients suffering from chronic obstructive pulmonary disease (COPD) has, until late 1990s, rarely been a subject of investigation.

Cigarette smoke, the most important risk factor for COPD, has a devastating potential for nasal mucosa, and may cause several nasal symptoms, ${ }^{5}$ impairment of mucociliary function, ${ }^{6}$ pathological signs of mucosal inflammation, ${ }^{7}$ and other changes. ${ }^{8}$ Montnémery and colleagues ${ }^{9}$ reported a prevalence of respiratory symptoms in about $40 \%$ of Swedes self-reporting chronic bronchitis or emphysema, compared 
to approximately $30 \%$ of the general population; whereas other authors report a much higher prevalence, reaching as much as $88 \%{ }^{10}$ Rhinosinusitis in COPD has been studied by few authors; only in the context of: nasal symptoms and their impact on quality of life; character of mucosal inflammation; and the relationship of upper airway disease to smoking and disease severity. So far, not all results are conclusive. For example, it is still not clear, how the severity of COPD, which according to many authors reflects the degree of lower airways inflammation, ${ }^{11}$ influences the degree of inflammation in the nose. It is also not known, what the relationship is between rhinosinusitis and systemic inflammation in COPD. Finally, new noninvasive methods should be applied to assess upper airway inflammation in COPD. Therefore, the aim of this study was to test:

1. Whether nasal symptoms, mucosal changes, and mucociliary clearance are different in COPD when compared to healthy nonsmokers?

2. What is the impact of nasal symptoms on general quality of life?

3. Whether upper airway inflammation in COPD can be characterized by changes in nasal lavage cellular pattern and increased concentrations of eicosanoids?

4. What is the relationship between all measured parameters with smoking?

5. What is the relationship between all measured parameters with disease severity?

6. What is the relationship between all measured parameters with systemic inflammation?

\section{Patients and methods}

\section{Study population}

Forty-two patients with COPD (13 females), age 50-84 years (mean \pm standard deviation $[S D]=65 \pm 8$ years). We defined the following inclusion/exclusion criteria:

1. Inclusion criteria:
a. Diagnosis of COPD, forced expiratory volume/forced vital capacity $\left(\mathrm{FEV}_{1} / \mathrm{FVC}\right)<70 \%$.
b. Age $\geq 40$.

2. Exclusion criteria:

a. Asthma and other chronic respiratory disorders.

b. Infection in the last 4 weeks.

c. Severe diseases that could influence the results of examinations (eg, cancer, uncompensated diabetes, tuberculosis).

d. Patients treated with $\mathrm{H} 1$ receptor inhibitors, intranasal and systemic steroids, local and systemic decongestants, drugs known to induce rhinitis in the last 4 weeks.

e. Domiciliary oxygen therapy and noninvasive ventilation.

f. Pregnancy and lactation.

g. Severe anatomical changes of nasal cavities.

h. Alcohol and drug abuse.

Asthma was excluded and COPD was confirmed on the basis of the lack of typical asthmatic symptoms, negative history of allergy, negative skin prick tests, late disease onset ( $>40$ years of age), the presence of severe smoking history ( $>20$ pack-years) and the presence of irreversible obstruction in spirometry. According to GOLD criteria, ${ }^{12}$ stage I was diagnosed in four patients, stage II in 11 patients, stage III in 19 patients and stage IV in eight patients. The group was divided into mild/moderate (stage I plus II) and severe/very severe (stage III plus IV). Patients were also divided into subgroups of present and exsmokers.

\section{Control group}

The control group consisted of 21 healthy subjects who have never smoked (10 females, age $59 \pm 9$ years). The substantial impact of passive smoking was disregarded. Exclusion criteria for this group included:

a. COPD.

b. Chronic lower and upper airways diseases (including asthma and allergy).

c. Infection in the last 4 weeks.

d. Systemic diseases (eg, diabetes).

e. Necessity of any chronic pharmacological treatment.

f. Smoking (ever).

All participants signed informed consent. The study was approved by the Ethics Committee at The Medical University of Lodz (consent number RNN $1307 \mathrm{KE}$ ).

\section{Nasal symptoms}

Nasal symptoms were assessed by a specific validated SinoNasal Assessment Questionnaire (SNAQ-11), consisting of 11 nose, sinus, and general items. ${ }^{13}$ Total score of 0 was the lowest and 80 was the highest possible.

\section{Quality of life}

Quality of life was estimated by a validated, self-administered, airway disease-specific and commonly used St. George's Respiratory Questionnaire (SGRQ) ${ }^{14}$ which consisted of 50 items grouped into three subscales: symptoms, activity and 
impact on health. SGRQ scores were calculated with the help of score calculator. ${ }^{15}$

\section{Spirometry}

Spirometry was measured according to European Respiratory Society (ERS) criteria, ${ }^{16}$ on computer-based spirometer (Jaeger, Germany). FEV ${ }_{1}$ and FVC results were presented as a $\%$ of predicted values. $\mathrm{FEV}_{1} / \mathrm{FVC}$ was calculated from best values achieved.

\section{BODE index}

BODE index (Body mass index; Obstruction; Dyspnea; Exercise capacity) was calculated, as previously described. ${ }^{17}$ The lowest number of scores is 0 , and the highest is 10 . The higher number indicates the worse prognosis of COPD. ${ }^{17}$

\section{Routine laboratory tests}

Peripheral blood was taken for C-reactive protein (CRP), erythrocyte sedimentation rate (ESR), morphology with estimation of white blood count (WBC) and hematocrit (HTC). Arterialized capillary blood from a fingertip was taken for blood gas analysis. Electrocardiogram (ECG) and chest X-ray were performed seeking signs of cor pulmonale. In case of the presence of such abnormalities in patients with $\mathrm{FEV}_{1}$ between 30\%-50\% predicted, they were qualified as COPD stage IV. ${ }^{12}$

\section{Nasal endoscopic examination}

Nasal endoscopic examination was performed with a fiberscope with external diameter of $4 \mathrm{~mm}$ (Pentax, Japan). Mucosal changes were estimated according to modified Lund-Kennedy scale. ${ }^{18}$ Each nasal cavity was examined separately and the following scoring system was applied: edema (0-2); polyps (0-1); discharge (0-3); and hyperemia (0-1). The possible number of points ranged from 0 to 14 .

\section{Saccharine test}

A saccharine test was applied for estimation of mucociliary clearance. ${ }^{19}$ The time (in minutes) from application of saccharine crystals on the anterior edge of inferior nasal conchae to first feeling of sweet taste was a measure of the mucociliary clearance. Fifteen minutes was taken as a higher limit of normal values.

\section{Nasal lavage}

Nasal lavage (NAL) was collected as described. ${ }^{20}$ It was performed in a sitting position, with the head bowed to the chest. Six milliliters of $0.9 \% \mathrm{NaCl}$ was poured to a nasal cavity by a specifically adopted syringe with a rubber seal around the tip. The syringe was kept in position, closing a nasal cavity for
5 minutes, with the head still bowed to the chest. During this period patients breathed through the mouth. Afterwards the saline was aspirated to a syringe. The procedure was the repeated in the second nasal cavity. Recovery was always above $80 \%$. Collected fluid was centrifuged for 10 minutes (1600 rotations/ minute). The supernatant was collected by pipette, and stored at $-80^{\circ} \mathrm{C}$, until measurement of eicosanoids could be undertaken. The pellet was suspended in $1 \mathrm{~mL}$ of phosphate-buffered saline (PBS) for further cytological examination.

\section{Cytological examination of NAL}

The cytospin slides were stained with May-GrünwaldGiemsa stain. The percentage of neutrophils, macrophages, lymphocytes, eosinophils, basophils, and epithelial cells was then calculated.

\section{Measurement of immunoreactive eicosanoids}

Cysteinyl leukotrienes (CysLTs), leukotriene $\mathrm{B}_{4}\left(\mathrm{LTB}_{4}\right)$ and 8-isoprostane (8-IP) concentrations in NAL were measured by a specific enzyme immunoassay (EIA) kit (Cayman Chemical, Ann Arbour, MI). The detection limits were: $13 \mathrm{pg} / \mathrm{mL}$ for cysLT and $\mathrm{LTB}_{4}$ and $5 \mathrm{pg} / \mathrm{mL}$ for 8-IP. Levels of measured mediators below the detection limit were arbitrarily assumed to be half of the detection limit value. Finally, measured concentrations of eicosanoids were standardized for protein concentrations and expressed as $\mathrm{pg} / \mathrm{g}$ protein.

\section{Statistical analysis}

Data with a normal distribution were expressed as mean \pm standard error of means (SEM). Medians with 25 and 75 percentile were provided when data were not normally distributed. Unpaired $t$-test (for normally distributed data) or the Mann-Whitney test (for data without normal distribution) was used. When more than two groups were compared (controls versus COPD. All versus: smokers; exsmokers; or COPD stages), one-way ANOVA and Bonferroni post-test (for data with Gaussian distribution) or the Kruskall-Wallis followed by Dunn's multiple comparison test (for data without normal distribution), were used. The Spearman test (nonparametric) or Pearson test (for data with normal distribution) were applied to assess correlations. The $P$ value $\leq 0.05$ was assumed as statistically significant.

\section{Results}

The characteristics of both the study and control groups are provided in Table 1. 
Table I Characteristics of the study and control groups

\begin{tabular}{lllll}
\hline & Control group & COPD all & COPD I/II & COPD III/IV \\
\hline Number & 21 & 42 & 16 & 26 \\
Females [\%] & $10(48)$ & $13(3 I)$ & $4(25)$ & $9(35)$ \\
Age [years] & $59 \pm 9$ & $68 \pm 8$ & $66 \pm 9$ & $64 \pm 8$ \\
FEV, [\% predicted] & $104.2 \pm 2.7$ & $50.2 \pm 19.9$ & $69.7 \pm 17.4$ & $38.2+8.6$ \\
FVC [\% predicted] & $108.6 \pm 3.2$ & $75.4 \pm 18.4$ & $88.0 \pm 17.1$ & $67.1 \pm 14.2$ \\
FEV,/FVC [\%] & $81.2 \pm 1.1$ & $50.6 \pm 13.2$ & $60.6 \pm 6.9$ & $46.2 \pm 10.5$ \\
Pack-years & 0 & $35.8 \pm 13.7$ & $35.9 \pm 11.2$ & $35.7 \pm 15.3$ \\
Active smokers No [\%] & $0(0)$ & $13(31)$ & $4(25)$ & $9(35)$ \\
Cigarettes daily & 0 & $2.6 \pm 4.9$ & $2.6 \pm 5.7$ & $2.6 \pm 4.5$ \\
COPD duration [years] & NA & $6.7 \pm 0.6$ & $6.8 \pm 0.9$ & $6.7 \pm 0.7$ \\
\hline
\end{tabular}

Abbreviations: COPD, chronic obstructive pulmonary disease; $\mathrm{FEV}_{1}$, forced expiratory volume; FVC, forced vital capacity.

\section{COPD versus healthy subjects: nasal} symptoms, mucosal changes, mucociliary clearance

The total score in SNAQ-11 questionnaire was higher in COPD patients than in the control group: $3.38 \pm 0.80$ versus $23.93 \pm 1.94, P \leq 0.0001$, Figure 1 . Only one patient did not report any symptoms ( $2.3 \%$ versus $28.6 \%$ for controls). The most frequent symptom in COPD was cough $(92.3 \%$ of all patients versus none in controls). Other frequent symptoms were: lack of good nights/tiredness/fatigue; runny nose; nasal congestion, blocked nose and sneezing. The least frequent symptoms were: facial pain/pressure and earache/ear fullness. Results are presented in Table 2.

The number of scores in the endoscopic examination was higher in COPD than in controls (median, 25-75th percentile): $0,0-1.0$ versus 3.0, 2.0-5.0, $P \leq 0.001$, Figure 2 .

\section{$P<0.0001$}

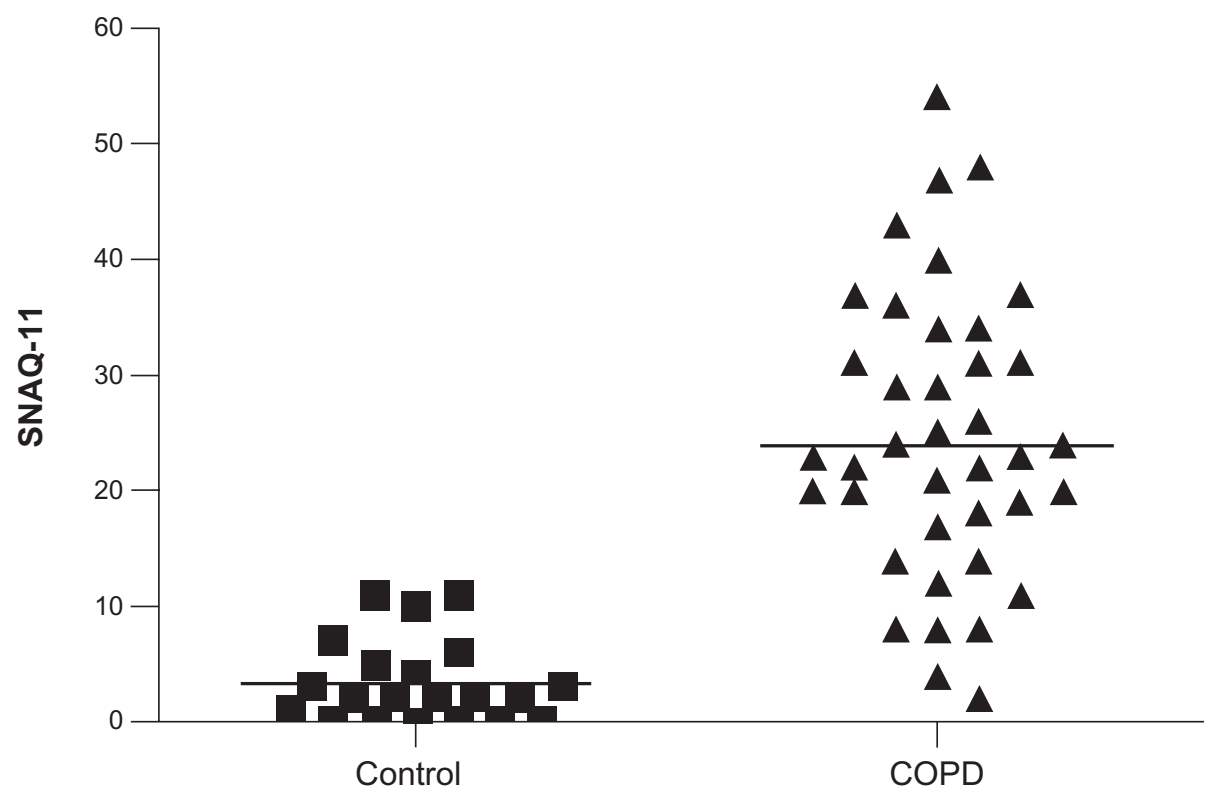

Figure I The results of SNAQ-II in healthy controls and COPD patients

Abbreviations: COPD, chronic obstructive pulmonary disease; SNAQ-II, Sino-Nasal Assessment Questionnaire. 
Table 2 Results of SNAQ-II and correlations of sino-nasal symptoms with SGRQ results in all COPD patients

\begin{tabular}{|c|c|c|c|c|c|c|}
\hline & Item & $\%$ all answers & SGRQ total & SGRQ symptoms & SGRQ activity & SGRQ impact \\
\hline \multirow[t]{2}{*}{$\mathrm{I}$} & Blocked nose & 76.9 & NS & $r=0.33$ & NS & NS \\
\hline & & & & $P=0.04$ & & \\
\hline \multirow[t]{2}{*}{2} & Nasal congestion/stuffy nose & 76.9 & NS & $r=0.38$ & NS & NS \\
\hline & & & & $P=0.02$ & & \\
\hline 3 & Facial pain/pressure & 20.5 & NS & NS & NS & NS \\
\hline 4 & Runny nose/anterior nasal discharge & 79.5 & NS & NS & NS & NS \\
\hline 5 & Postnasal discharge & 56.4 & NS & NS & NS & NS \\
\hline 6 & Sneezing & 76.9 & NS & NS & NS & NS \\
\hline 7 & Cough & 92.3 & NS & NS & NS & NS \\
\hline 8 & Reduced/altered smell & 35.9 & NS & NS & NS & NS \\
\hline 9 & Headache & 64.1 & NS & NS & NS & NS \\
\hline \multirow[t]{2}{*}{10} & Earache/ear fullness & 43.6 & $r=0.37$ & $r=0.38$ & $r=0.35$ & $r=0.35$ \\
\hline & & & $P=0.02$ & $P=0.02$ & $P<0.05$ & $P=0.04$ \\
\hline \multirow[t]{6}{*}{11} & Lack of good nights & 82.1 & $r=0.38$ & NS & $r=0.34$ & $r=0.38$ \\
\hline & sleep/tiredness/fatigue & & $P=0.02$ & & $P=0.04$ & $P=0.02$ \\
\hline & All & 97.6 & NS & $r=0.39$ & NS & NS \\
\hline & & & & $P=0.01$ & & \\
\hline & All - 7 (without cough) & 97.6 & NS & $r=0.35$ & NS & NS \\
\hline & & & & $P=0.03$ & & \\
\hline
\end{tabular}

Abbreviations: COPD, chronic obstructive pulmonary disease. NS, not significant; SGRQ, St. George Respiratory Questionnaire; SNAQ-I I, Sino-Nasal Assessment Questionnaire.

Time from the application of saccharine crystals to the first feeling of a sweet taste was longer in all COPD groups but did not reach statistical significance $(9.91 \pm 0.49$ versus $13.12 \pm 0.68, P>0.05$, Figure 3).
Positive correlations were found between the SNAQ-11 questionnaire and endoscopic scoring $(\mathrm{r}=0.58, P<0.0001$, Figure $4 \mathrm{~A})$ and mucociliary clearance time $(\mathrm{r}=0.51$, $P<0.0005$, Figure 4 B).

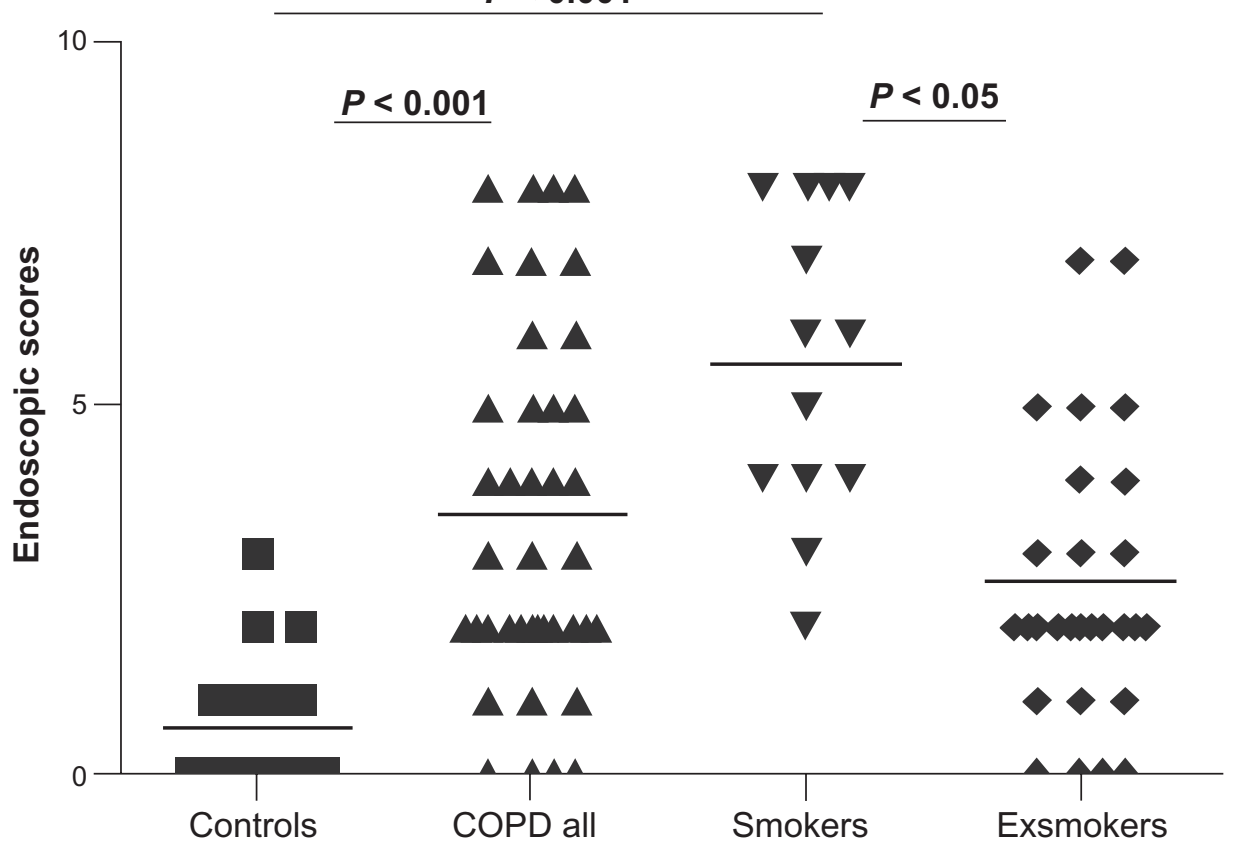

Figure 2 The results of endoscopic scores in healthy controls, all COPD patients, COPD active smokers, and COPD ex-smokers. Abbreviation: COPD, chronic obstructive pulmonary disese. 


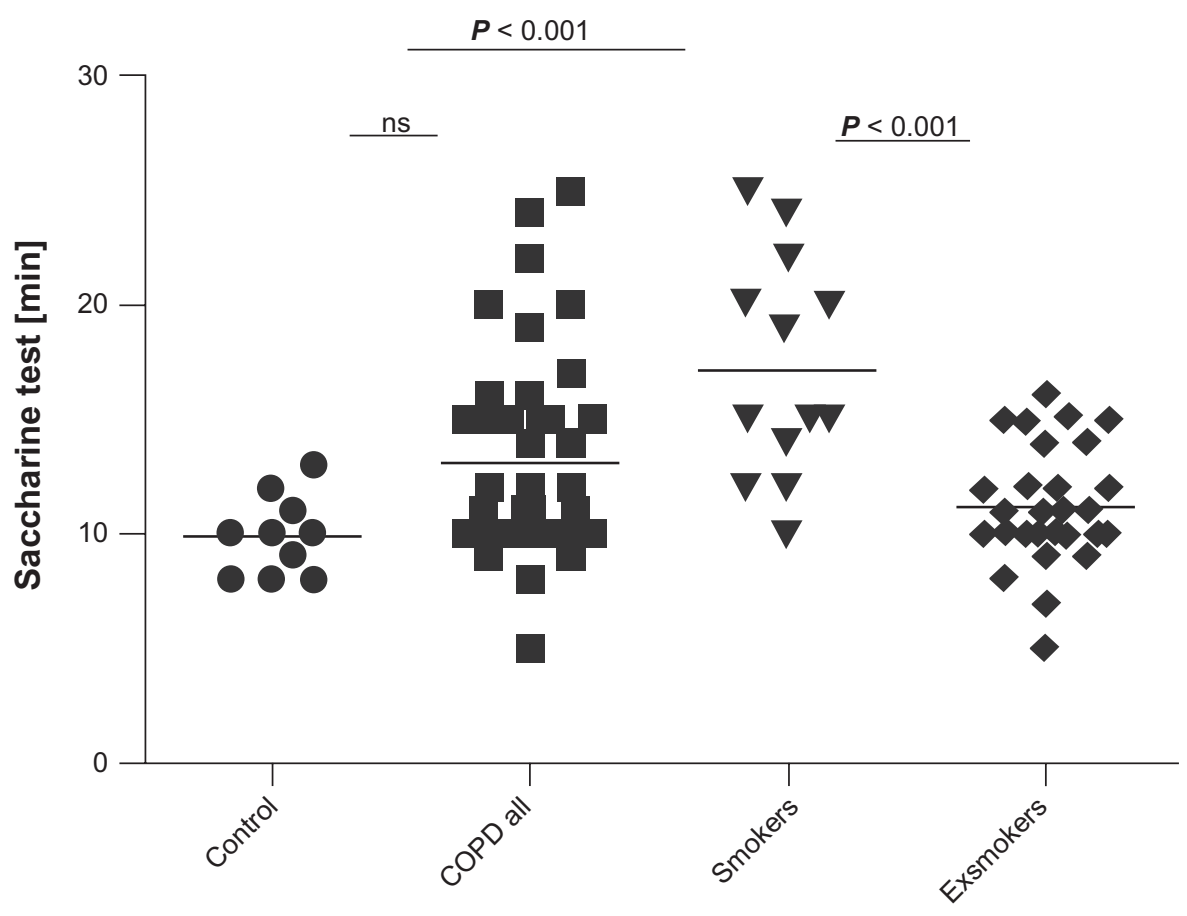

Figure 3 The results of saccharine test (in minutes) in healthy controls, all COPD patients, COPD active smokers, and COPD exsmokers. Abbreviation: COPD, chronic obstructive pulmonary disease.

\section{Nasal symptoms and general quality of life} Nasal symptoms (SNAQ-11) did not correlate with the total scores of SGRQ, activity, and impact subscores, regardless the cough item was calculated or not. Only weak correlation was found with symptoms subscore $(\mathrm{r}=0.34, P=0.035$, and when cough was subtracted: $\mathrm{r}=0.36, P=0.025)$. This correlation was related to blocked nose, nasal congestion/stuffy nose, and earache/ear fullness, but not to cough. No correlations were found between SGRQ total scores or subscores with endoscopic scoring and saccharine test results. See Table 2 for results.

\section{COPD vs controls: nasal lavage cells} and eicosanoids

There were no significant differences in nasal lavage cells percentage between COPD and controls. There was only a tendency towards higher values of lymphocytes in COPD: $10.3 \pm 2.0$ versus $16.8 \pm 2.3(P=0.067)$.

Nasal 8-IP were not higher in COPD compared to control values (median, $25-75$ percentile): $0.13,0.08-0.21$ versus $0.13,0.11-0.31 \mathrm{pg} / \mathrm{g}$ protein $(P=0.39)$. Similarly, there were no differences in cysLT $0.36,0.15-0.59$ versus 0.30 , $0.22-0.6(P=0.33)$ and LTB4 $0.57,0.29-1.5$ versus 0.6 , $0.19-1.01 \mathrm{pg} / \mathrm{g}$ protein $(P=0.10)$.

There were no correlations between nasal eicosanoids and percentage of nasal cells. Eicosanoids were mutually, strongly correlated: 8-IP versus LTB4 $(\mathrm{r}=0.59, P \leq 0.0001)$, 8 -IP versus cysLT ( $\mathrm{r}=0.6, P \leq 0.0001)$, LTB4 versus cysLT $(\mathrm{r}=0.61, P \leq 0.0001)$.

\section{Influence of smoking}

Symptoms were not different between smokers and exsmokers with COPD. There were no correlations between symptom scores and cumulative smoking consumption (pack-years) $(\mathrm{r}=-0.06, P=0.69)$.

Endoscopic scores were higher in smokers (median, 25-75th percentile: $6.25,4.75-8.0)$ than in controls $(0,0-1.0$, $P \leq 0.01)$ and in exsmokers (2.0, 1.5-4.0, $P \leq 0.05)$, Figure 2. With smokers, a correlation was found between endoscopic scores and daily cigarettes consumption $(\mathrm{r}=0.60$, $P \leq 0.0001)$.

The saccharine test revealed longer mucociliary clearance time in COPD smokers than in controls $(9.91 \pm 0.49$ versus $16.31 \pm 1.57$ minutes, $P \leq 0.001)$ and in exsmokers $(11.21 \pm 0.48, P \leq 0.01)$, Figure 3 . Saccharine test results correlated with actual cigarette consumption $(\mathrm{r}=0.43, P=0.005)$.

NAL cells were not different between smokers and exsmokers and between smokers and controls.

Nasal 8-IP concentrations were higher in COPD smokers than in controls: $0.17 \pm 0.04$ versus $0.34 \pm 0.09, P=0.049$, Figure 5. Positive correlation was found with actual cigarette 


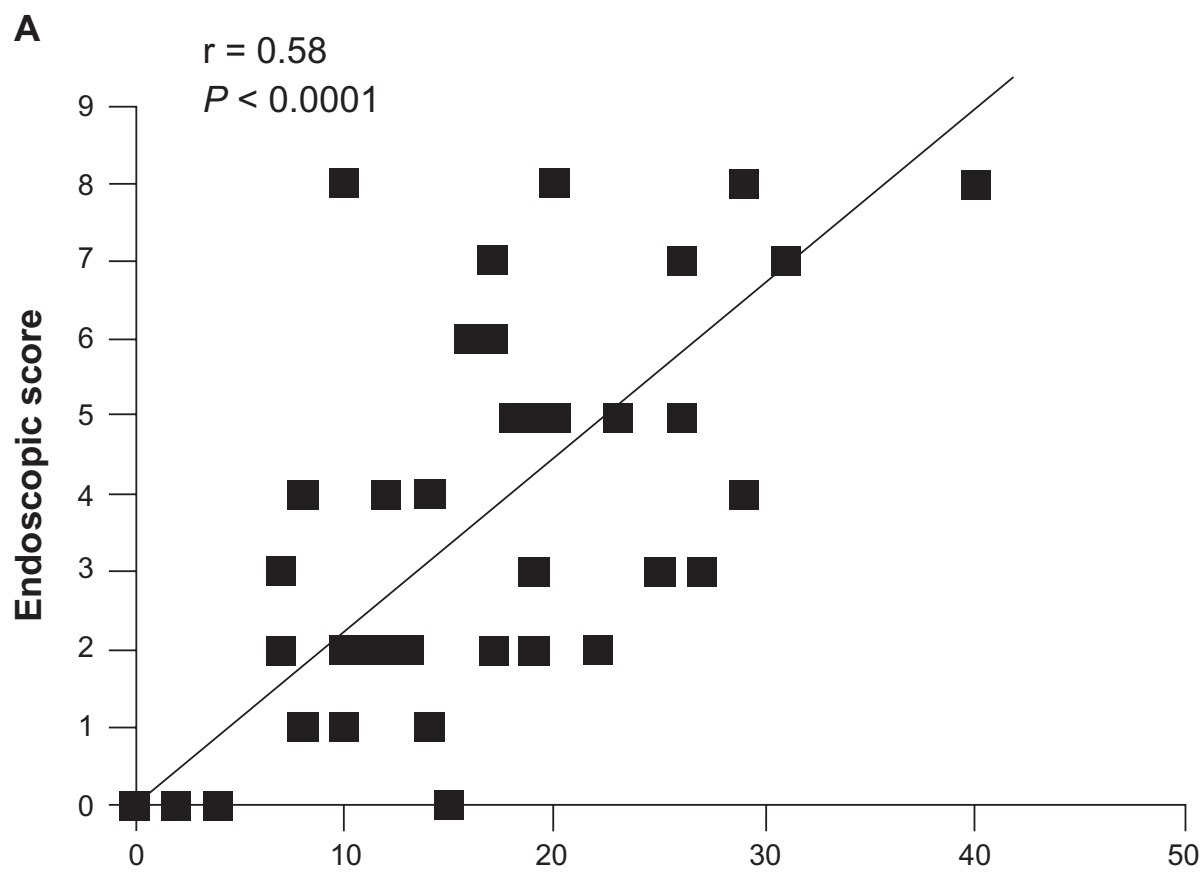

SNAQ-11

B

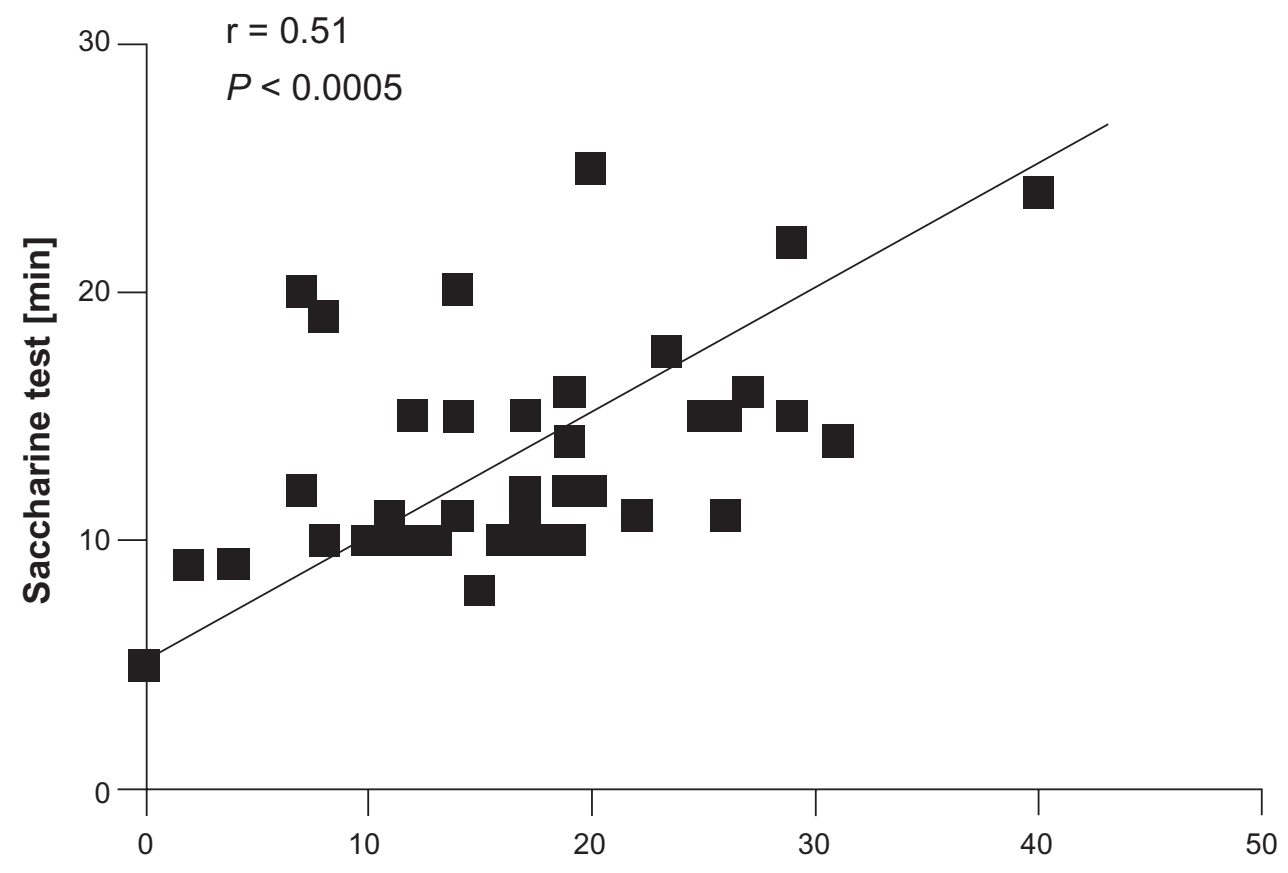

SNAQ-11

Figure 4 Correlations between SNAQ-1I results with endoscopic score (A) and saccharine test (B) in all COPD patients. Abbreviations: COPD, chronic obstructive pulmonary disease; SNAQ-I I, Sino-Nasal Assessment Questionnaire. 


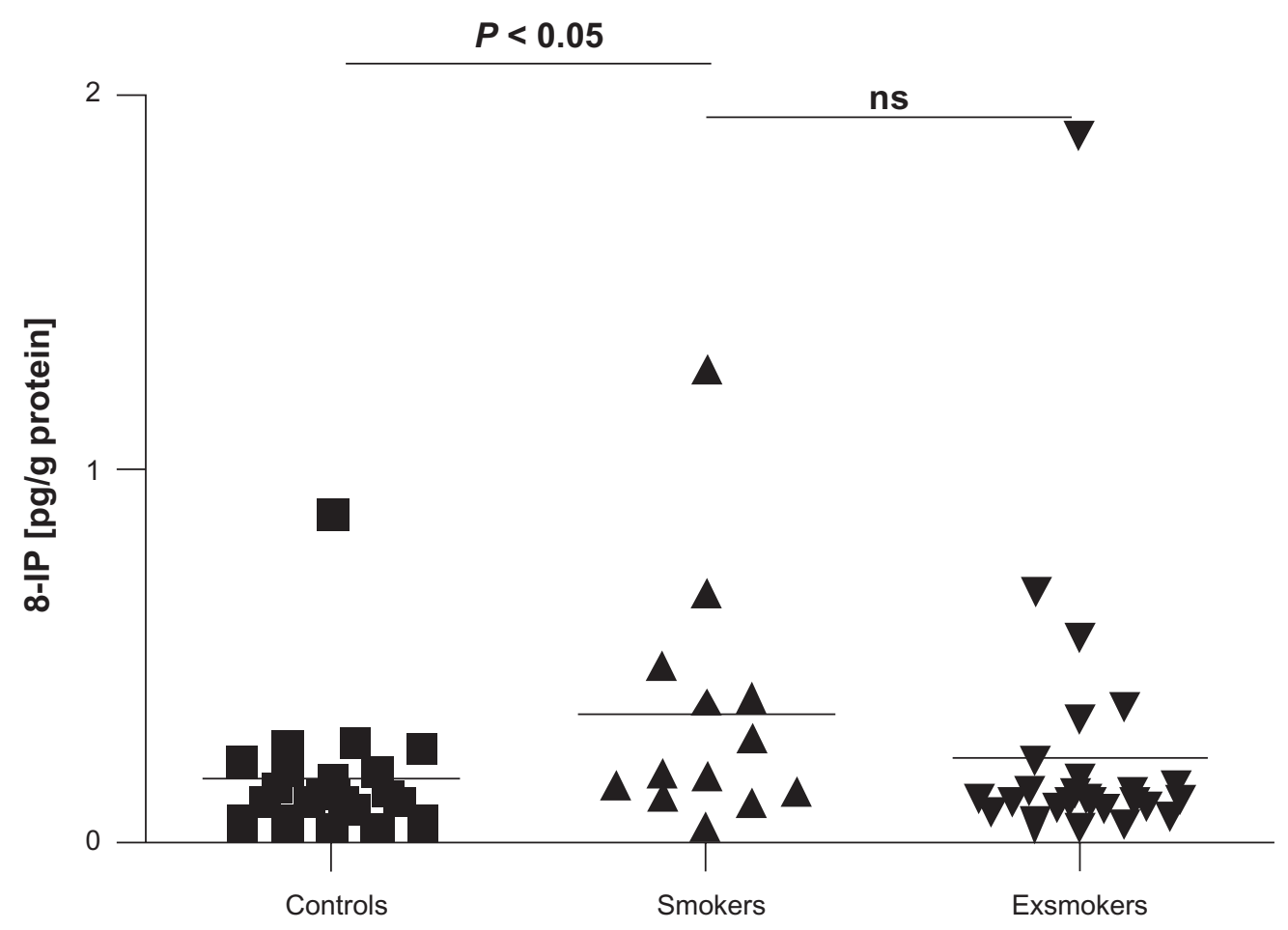

Figure 5 Concentrations of 8-isoprostane (8-IP) in nasal lavage (pg/g protein) in healthy subjects, COPD smokers, and exsmokers. Abbreviation: COPD, chronic obstructive pulmonary disease.

consumption $(\mathrm{r}=0.37, P=0.02)$ and negative with time from smoking cessation $(\mathrm{r}=0.35, P=0.02)$.

\section{COPD severity and rhinosinusitis}

Symptoms, endoscopic score, saccharine test results, cellular profile of NAL, NAL eicosanoids were not different between GOLD stages. There were no correlations of these parameters with $\mathrm{FEV}_{1}$, BODE index and its components, partial pressure of oxygen in arterial blood $\left(\mathrm{PaO}_{2}\right)$ and $\mathrm{PaCO}_{2}$.

\section{Markers of systemic inflammation and rhinosinusitis}

No correlations were found between SNAQ-11 score, endoscopic score, saccharine test results, cellular profile of NAL, NAL eicosanoids, and CRP, ESR or WBC.

\section{Discussion}

\section{Nasal symptoms, mucosal changes, and mucociliary clearance in COPD}

Although our study group was relatively small, the frequency of symptomatic patients close to $98 \%$ (at least one symptom) is unequivocal, and fully consistent with the results of others. ${ }^{9,10}$ The structure of symptoms seems to be quite significant for this group of patients. The most frequent symptoms, cough and lack of good night's sleep/tiredness/ fatigue may be related more to COPD rather than to upper airway disease. When these symptoms are excluded, the typical rhinitis symptoms become most prevalent. The least frequent symptoms are related to sinus and ear. The same symptom structure was reported by Montnémery and colleagues, ${ }^{9}$ although assessed by different methods.

A strong positive correlation between SNAQ-11 scores and endoscopic scores was found in our study and is in opposition to the results of Tahamiler and colleagues ${ }^{21}$ who found that $75 \%$ of patients with symptom-based diagnosis of chronic nonallergic rhino-sinusitis had no endoscopic pathology. Similar doubts on the value of symptom-based diagnosis of chronic rhinosinusitis have been raised by others. ${ }^{22}$ We believe, that the good correlation of symptom and endoscopic scores in our study may be explained by homogenous population of patients, who suffered from a disease (COPD) with known high prevalence of rhinosinusitis, and not in the general non-predefined population, as it was in case of cited studies.

Mucociliary clearance time measured by the saccharine test may be treated as another objective measure characterizing rhinitis in COPD. It reflects one of the main physiologic features of upper and lower airway inflammation in smoking-related COPD. There may be a variety of 
mechanisms involved in mucociliary clearance impairment in COPD, including decrease of cilia density on the nasal epithelium, increase of mucus viscosity, ion transport disturbances or impairment of cilia activity. ${ }^{23-25}$

\section{Nasal symptoms and quality of life}

Some authors suggest, that upper airway symptoms impair the overall quality of life in COPD patients. ${ }^{10}$ There is even speculation that treatment of rhinosinusitis may substantially improve quality of life of these patients. ${ }^{26}$ Hurst and colleagues ${ }^{10}$ reported decreased quality of life assessed by Sino-Nasal Outcome Test (SNOT-20) questionnaire, which is specific for rhinosinusitis but contains general items evaluating quality of life. Based on their results it was concluded, that rhino-sinal disease impairs quality of life of these patients. However, no correlation was found between SNOT-20 and SGRQ, which led the authors to suggest, that these effects may not be detected by currently available tools (SGRQ), which focus mainly on lower respiratory tract symptoms. Our results show a positive correlation with the symptoms subscale of SGRQ, suggesting that the more symptomatic COPD, the more symptomatic rhinosinusitis. Total, activity and impact scores were not correlated. The analysis of the particular items of SNAQ-11 questionnaire indicated, that blocked nose and nasal congestion may be responsible for this relationship. Earache/earfulness influenced all parts of SGRQ, but this symptom was relatively rare. More important is the analysis of symptoms which are non-specific for upper airway disease, like cough and disturbed nights sleep, tiredness, fatigue. The latter was a frequent complaint and correlated with total, activity and impact subscores, but not with symptoms. The most frequent item, cough, was not correlated with any of SGRQ subscores and the subtraction of this symptom did not result in losing statistical significance of the above mentioned correlations. Therefore we conclude, that rhino-sinal disease influence COPD-related symptoms but not the general quality of life assessed by SGRQ.

\section{Nasal lavage cells and eicosanoids}

Providing nasal mucosal changes reflect bronchial inflammation in COPD, we should expect that the most prominent cells in nasal lavages are neutrophils. In our study we have not found any differences in the percentage of neutrophils. Also there were no differences in relation to other cell types between COPD and healthy nonsmokers. In the study of Nihlén and colleagues, ${ }^{27}$ concentrations of myeloperoxidase (MPO) in NAL, a marker of neutrophil activity, was not higher in COPD, but MPO levels exhibited a greater increase from baseline at histamine challenge in these patients compared to controls. Moreover, in patients' reporting nasal symptoms this increase was especially high. These observations provide only indirect proof for the involvement of neutrophils. More direct evidence of neutrophils involvement was provided by Vachier and colleagues, ${ }^{28}$ who found increased numbers of neutrophils in nasal biopsies of smokers with COPD, compared to smokers without COPD and healthy subjects. In this exclusive study (the only one based on nasal mucosal biopsy) increased number of CD8 T lymphocytes was also confirmed. Not surprisingly, these features of nasal inflammation were concordant with bronchial inflammation, and confirmed the pan-airway disease idea in COPD.

To the best of our knowledge, this study is the first to apply eicosanoids in nasal lavages to assess upper airway inflammation in COPD. We measured cysteinyl leukotrienes (cysLT) - a marker of eosinophil activity, leukotrienes B4 (LTB4) - a marker of neutrophil activity, and 8-isoprostane (8-IP), - a product of nonenzymatic peroxidation of arachidonic acid, which has been proven to be a reliable marker of lipid peroxidation. ${ }^{29}$ These markers were measured in broncholaveolar lavage fluid, induced sputum or exhaled breath condensate (EBC) of asthma and COPD patients. For example, sputum 8-IP is elevated in asymptomatic smokers, ${ }^{30}$ LTB4 in sputum/EBC are elevated in stable ${ }^{31}$ and exacerbated COPD, ${ }^{32}$ and exhaled breath cysLT concentrations are elevated in asthma. ${ }^{33}$ Unfortunately, we could not present any differences in concentrations of NAL eicosanoids between COPD and control subjects. Also, eicosanoids were not correlated with nasal lavage cells, specifically there were no correlations between NAL neutrophils and LTB4 or 8-IP (neutrophils are a source of reactive oxygen species and neutrophillic inflammation is linked to oxidative stress). In view of our results it is probable, that only biopsy of nasal mucosa could prove the presence of the typical features of COPD-like inflammation in the nose. Although the biopsy of nasal mucosa was included in the primary protocol of our study and we received consent from ethical committee to perform biopsy, we were forced to resign from this procedure due to high rate of patients' refusals.

\section{Rhinosinusitis and smoking}

In epidemiological studies COPD and rhinitis are related to common predisposing factors: smoking; age; and sex. ${ }^{34}$ We provide data showing, that active smokers with COPD have more intensive inflammation as assessed by endoscopic scores and the saccharine test. Prolonged mucociliary clearance in COPD smokers in our study is in agreement with 
the results of Stanley and colleagues, ${ }^{6}$ who also found, that decreased mucociliary clearance in smokers is not related to decreased ciliary beat frequency. No differences were found between smokers and ex-smokers or healthy never-smokers in the cellular content of NAL. We did not find any correlations between nasal cells (specifically neutrophils and eosinophils) and cumulative or current cigarette consumption. However, there was a difference between COPD smokers and healthy controls in nasal 8-IP concentration. Moreover, NAL 8-IP concentrations correlated positively with current smoking consumption. All these confirm the role of smoking in upper airway inflammation and suggest that in those who quit smoking, some improvement of rhinosinusitis may be achieved. Smoking is a well known trigger of oxidative stress. Smoke itself is a rich source of free radicals; various oxidants may be released from activated inflammatory cells, like neutrophils and eosinophils. ${ }^{28}$ Arachidonic acid, a natural substrate for 8-IP, may be released from cellular membranes of injured epithelia. As suggested before, evidence of less intensive rhinitis in COPD patients who managed to quit smoking compared to smoking COPD subjects-regardless of age, cumulative cigarette consumption and COPD severity-suggests partial reversibility of upper airway disease. It has been acknowledged for years, that smoking cessation improves symptoms and slows lung function decline in COPD. ${ }^{12}$ Lapperre and colleagues reported that the infiltration of bronchial mucosa in COPD patients with CD8+ T lymphocytes decreases gradually with time after smoking cessation. ${ }^{35}$ Therefore it may be speculated, that smoking cessation may decrease upper airway inflammation.

In order to fully acknowledge the influence of smoking on rhinosinusitis in COPD, our results should have been compared with a group of non-COPD smokers. The lack of such a control group is a limitation of our study.

\section{Rhinosinusitis and COPD severity}

The literature provides ambiguous data on this subject. Hurst and colleagues reported that decreased nasal patency measured by acoustic rhinometry is proportional to the degree of airflow obstruction. ${ }^{36}$ Although we have not used any methods to objectively measure nasal patency, none of the measured parameters characterizing rhinosinusitis were correlated with $\mathrm{FEV}_{1}$, BODE index and its components. The same group of authors neglects the relationship between nasal inflammatory markers and $\mathrm{FEV}_{1}{ }^{37}$

\section{Rhinosinusitis and systemic inflammation}

The question arises, whether upper airway disease is one of the elements of COPD-related systemic inflammatory disease. We correlated all measured parameters with markers of systemic inflammation, such as CRP, ESR or WBC, and did not find any correlations. Similar negative results were presented by others in stable disease in relation to serum IL-6, ${ }^{37}$ and during COPD exacerbations, when serum CRP and IL-6 were measured. ${ }^{38}$

\section{Conclusions}

1. Our results confirm the high prevalence of rhinosinusitis in COPD

2. We could not provide data on the substantial impact of rhinosinusitis symptoms on general quality of life assessed by SGRQ

3. Nasal lavage cellular pattern and eicosanoids do not differentiate COPD patients from healthy subjects

4. Active smoking is connected with more severe upper airway inflammation

5. Upper airway disease is not strictly related to COPD severity

6. No evidence was found for the relationship between nasal symptoms and other features of upper airway disease with systemic inflammation.

\section{Disclosures}

The authors report no conflicts of interest in this work.

\section{References}

1. Leynaert B, Neukirch F, Demoly P, Bousquet J. Epidemiologic evidence for asthma and rhinitis comorbidity. JAllergy Clin Immunol. 2000;106: S201-S205.

2. Bachert C, Patou J, Van Cauwenberge P. The role of sinus disease in asthma. Curr Opin Allergy Clin Immunol. 2006;6:29-36.

3. Magnan A, Romanet S, Vervloet D. Rhinitis, nasal polyposis and asthma: clinical aspects. In: Wallaërt B, Chanes P, Godard P, editors. The nose and lung diseases. European Respiratory Monograph. 2001;6:101-114.

4. Nutku E, Toda M, Hamid QA. Rhinitis, nasal polyposis and asthma: pathological aspects. In: Wallaërt B, Chanes P, Godard P, editors. The nose and lung diseases. European Respiratory Monograph. 2001;6:115-142.

5. Bascom R. The upper respiratory tract, mucus membrane irritation. Environ Health Perspectives. 1991;95:39-44.

6. Stanley PJ, Wilson R, Greenstone MA, MacWilliam L, Cole PJ. Effect of cigarette smoking on nasal mucociliary clearance and ciliary beat frequency. Thorax. 1986;41:519-523.

7. Vachier I, Vignola AM, Chiappara G, et al. Inflammatory features of nasal mucosa in smokers with and without COPD. Thorax. 2004;59:303-307.

8. Phillips DE, Hill L, Weller P, Willett M, Bakewell R. Tobacco smoke and the upper airway. Clin Otolaryngol. 2003;28:492-496.

9. Montnémery P, Svensson C, Ädelroth E, et al. Prevalence of nasal symptoms and their relation to self-reported asthma and chronic bronchitis/emphysema. Eur Respir J. 2001;17:596-603.

10. Hurst JR, Wilkinson TMA, Donaldson GC, Wedzicha JA. Upper airway symptoms and quality of life in chronic obstructive pulmonary disease (COPD). Respir Med. 2004;98:767-770. 
11. Donaldson GC, Seemungal TA, Patel IS, et al. Airway and systemic inflammation and decline in lung function in patients with COPD. Chest. 2005;128:1997-2004.

12. NHLBI/WHO. Global Initiative for Chronic Obstructive Lung Disease (GOLD). www.goldcopd.org. (accessed February 2010).

13. Fahmy FF, McCombe A, Mckiernan DC. Sino-nasal assessment questionnaire, a patient focused, rhinosinusitis specific outcome measure. Rhinology. 2002;40:195-197.

14. Ferrer M, Villasante C, Alonso J, et al. Interpretation of quality of life scores from the St George's Respiratory Questionnaire. Eur Respir J. 2002;19:405-413.

15. St. Georges Respiratory Questionnaire (SGRQ). http://www.csp.org. uk/director/members/practice/clinicalresources/outcomemeasures/ searchabledatabase.cfm?item_id = 57011C3CC18E1DDB45B5FF27 C979B2A0 Accessed February 2010.

16. Pellegrino R, Viegi G, Brusasco V, et al. ATS/ERS Task Force: Standardisation of lung function testing. Interpretative strategies for lung function tests. Eur Respir J. 2005;26:948-968.

17. Celli BR, Cote CG, Lareau SC, Meek PM. Predictors of survival in COPD:more than just the $\mathrm{FEV}_{1}$. Respir Med. 2008;102:S27-S35.

18. Lund VJ, Kennedy DW. Quantification for staging sinusitis. International Conference on Sinus Disease: Terminology, Staging, Therapy. Ann Otol Rhinol Laryngol Suppl. 1995;104 (Suppl):17-21.

19. Stanley P, MacWilliam L, Greenstone M. Efficacy of a saccharin test for screening to detect abnormal mucociliary clearance. Br J Dis Chest. 1984;78:62-65.

20. Greiff L, Pipcorn U, Alkner U, Persson CG. The nasal pool device applies controlled concentrations of solutes on human nasal airway mucosa and samples its surface secretions. Clin Exp Allergy. 1990;20:253-259.

21. Tahamiler R, Canakcioglu S, Ogreden S, Acioglu E. The accuracy of symptom-based definition of chronic rhinosinusitis. Allergy. 2007;62:1029-1032.

22. Stankiewicz J, Chow JM. Nasal endoscopy and the definition and diagnosis of chronic rhinosinustis. Otolaryngol Head Neck Surg. 2002;126:623-627.

23. Mall MA. Role of cilia, mucus, and airway surface liquid in mucociliary dysfunction:lessons from mouse models. J Aerosol Med Pulm Drug Deliv. 2008;21:13-24.

24. Danahay H, Jackson AD. Epithelial mucus-hypersecretion and respiratory disease. Curr Drug Targets Inflamm Allergy. 2005;4:651-664.

25. Liotè H, Zahm JM, Pierrot D, Puchelle E. Role of mucus and cilia in nasal mucociliary clearance in healthy subjects. Am Rev Respir Dis. 1989;140:132-136.
26. Kim JS, Rubin BK. Nasal and sinus involvement in chronic obstructive pulmonary disease. Curr Opin Pulm Med. 2008;14:101-104.

27. Nihlén U, Andersson M, Löfdahl CG, Persson CGA, Montnémery P, Greiff L. Nasal neutrophil activity and mucinous secretory responsiveness in COPD. Clin Physiol Func Im. 2003;23:138-142.

28. Vachier I, Vignola AM, Chiappara G, et al. Inflammatory features of nasal mucosa in smokers with and without COPD. Thorax. 2004;59:303-307.

29. Morrow JD, Frei B, Longmire AW, et al. Increase in circulating products of lipid peroxidation ( $\mathrm{F}_{2}$-isoprostane) in smokers. Smoking as a cause of oxidative damage. $N$ Eng J Med. 1995;332:1198-1203.

30. Kinnula VL, Ilumets H, Myllärniemi M, Sovijärvi A, Rytilä P. 8-Isoprostane as a marker of oxidative stress in nonsymptomatic cigarette smokers and COPD. Eur Respir J. 2007;29:51-55

31. Kostikas K, Gaga M, Papatheodorou G, Karamanis T, Orphanidou D, Loukides S. Leukotriene B4 in exhaled breath condensate and sputum supernatant in patients with COPD and asthma. Chest. 2005;127: 1482-1485.

32. Bathoorn E, Liesker JJ, Postma DS, et al. Change in inflammation in outpatient COPD patients from stable phase to a subsequent exacerbation. Int J Chron Obstruct Pulmon Dis. 2009;4:101-109.

33. Antczak A, Montuschi P, Kharitonov S, Gorski P, Barnes PJ. Increased exhaled cysteinyl-leukotrienes and 8-isoprostane in aspirin-induced astma. Am J Respir Crit Care Med. 2002;166:301-306.

34. Sichletidis L, Tsiotsios I, Gavriilidis A, et al. Prevalence of chronic obstructive pulmonary disease and rhinitis in Nothern Greece. Respiration. 2005;72:270-277.

35. Lapperre TS, postma DS, Gosman MME, et al; on behalf of the GLUCOLD Study Group. Relation between duration of smoking cessation and bronchial inflammation in COPD. Thorax. 2006;61:115-121.

36. Hurst JR, Kuchai R, Michael P, Perera WR, Wilkinson TMA, Wedzicha JA. Nasal symptoms, airway obstruction and disease severity in chronic obstructive pulmonary disease. Clin Physiol Funct Imaging. 2006;26:251-256.

37. Hurst JR, Wilkinson TMA, Perera WR, Donaldson GC, Wedzicha JA. Relationship among bacteria, upper airway, lower airway, and systemic inflammation in COPD. Chest. 2005;127:1219-1226.

38. Hurst JR, Perera WR, Wilkinson TMA, Donaldson GC, Wedzicha JA. Systemic and upper and lower airway inflammation at exacerbation of chronic obstructive pulmonary disease. Am J Respir Crit Care Med. 2006;173:71-78.
International Journal of COPD

\section{Publish your work in this journal}

The International Journal of COPD is an international, peer-reviewed journal of therapeutics and pharmacology focusing on concise rapid reporting of clinical studies and reviews in COPD. Special focus is given to the pathophysiological processes underlying the disease, intervention programs, patient focused education, and self management protocols.

\section{Dovepress}

This journal is indexed on PubMed Central, MedLine and CAS. The manuscript management system is completely online and includes a very quick and fair peer-review system, which is all easy to use. Visit http://www.dovepress.com/testimonials.php to read real quotes from published authors. 